\title{
DIAGNÓSTICO DA DOENÇA DO REFLUXO GASTROESOFÁGICO: opções e critérios
}

DESCRITORES - Esofagite. Refluxo gastroesofágico.

A publicação neste número dos ARQUIVOS de GASTROENTEROLOGIA de artigo que busca reavaliar a sensibilidade da pHmetria esofágica ${ }^{(5)}$ reativa discussão sobre os conceitos que norteiam a busca diagnóstica da afecção.

A pHmetria esofágica tem firme fundamentação. Não é método de verificação pura e simples de $\mathrm{pH}$ esofágico casual, mas sim capaz de quantificar o refluxo ácido durante tempo prolongado, identificar a capacidade do esôfago em "devolver ao estômago" o volume refluído (observando-se a duração dos episódios de refluxo), verificar a freqüência, em que período e com que postura o fenômeno ocorre e ainda correlacionar o sintoma referido com os momentos em que realmente existe redução do $\mathrm{pH}$ esofágico.

Este último aspecto mimetiza os testes provocativos, pois o refluxo em si exerce o papel do ácido que estaria sendo perfundido no órgão para verificar se determina o aparecimento de dor, pirose, enfim dá base ao quadro clínico que motivou a pesquisa diagnóstica.

O surgimento de sondas e eletrodos extremamente finos e macios tem feito com que o exame seja cada vez mais confortável, muito bem aceito, inclusive por crianças, nas quais talvez seja o recurso diagnóstico de eleição para as várias afecções, inclusive extradigestivas, decorrentes do refluxo gastroesofágico $^{(4)}$.

Limitações existem, como em todo procedimento biológico ${ }^{(3)}$. A própria presença da sonda no interior do esôfago pode modificar seu comportamento motor, alterando seu ritmo de esvaziamento e até aumentar a produção de saliva, subestimando os níveis ácidos intraesofágicos.
Além disto, depende-se de calibração e adequada programação do sistema de análise computadorizada, sem contar a necessidade de colaboração do paciente, evitando comportamento retraído por estar portando os dispositivos, mas mantendo a recomendada restrição dietética no período de realização do exame.

São ainda discutíveis as padronizações do nível 4 como divisor do "normal" para o "patológico", em termos de $\mathrm{pH}$ esofágico, e de $5 \mathrm{~cm}$ acima da borda superior do esfíncter inferior do esôfago como nível de posicionamento do eletrodo.

Os expressivos desvios-padrão na obtenção das médias dos vários parâmetros analisados pela $\mathrm{pHmetria}$ esofágica prolongada em série de pacientes ${ }^{(6)}$ coloca às claras a distribuição "não normal" dos resultados em termos estatísticos.

No entanto, é clássico que séries de portadores de esofagite severa são as que apresentam os maiores índices de pHmetria prolongada do esôfago alterada, como no trabalho de FLORAFILHO et al. ${ }^{(5)}$.

Por outro lado, não se deve esquecer que as formas mais graves da doença do refluxo gastroesofágico (DRGE) implicam estenose do esôfago distal, que constitui óbice à realização da pHmetria, pois o refluxo fica impossibilitado de atingir o eletrodo, falseando grosseiramente os resultados.

Este importante aspecto não é o único a dificultar a valorização de estudos que comparam acurácia de procedimentos diagnósticos da DRGE ou que buscam detectar a sensibilidade de um exame, tomando outro por base.

As radiografias contrastadas do esôfago, embora de grande valor na identificação da hérnia hiatal, perderam terreno para 
a endoscopia, mas este também não é recurso completo para diagnóstico da DRGE. Evidencia o aspecto da mucosa com nitidez, mas mesmo assim os critérios de avaliação da agressão permanecem controversos e as classificações da esofagite variam a toda hora.

Além disso, é impossível aferir o quanto o aspecto normal da mucosa, quando visualizado, não é dependente exclusivamente de maior produção salivar, de muco ou de mediadores antiinflamatórios locais compensatórios, ou mesmo de mudança do comportamento motor do esôfago, acelerando seu esvaziamento, livrando o órgão rapidamente de refluxo persistente.

Estes mecanismos de defesa podem ser suficientes para manter aspecto normal da mucosa, mas não para bloquear o nociceptivo, assim explicando porque indivíduos muito sintomáticos podem apresentar exame endoscópico sem alterações.

A endoscopia permite a realização de biopsias, mas o estudo histológico das amostras está longe de ser definitivo para caracterização de DRGE. Os problemas já começam na escolha do local em que devem ser obtidos os fragmentos de mucosa, extremamente controverso, e seguem quando se analisam os critérios a serem utilizados pelo patologista em busca de alterações teciduais "características de doença do refluxo". Baseiam-se em medições microscópicas e proporcionais (espessamento da camada basal "de mais de $15 \%$ da espessura total do epitélio", extensão das papilas "para dois terços da camada epitelial total"), de credibilidade extremamente discutível, pela questionabilidade da padronização adotada e pela dificuldade técnica de análise, indutora de erros.

Mais ainda, considere-se que a chegada de neutrófilos aos tecidos pode ser interpretada como reação aguda, assim como extravasamento de elementos intravasculares também pode ser resposta a momentânea e frustra agressão à mucosa esofágica, até por hábitos alimentares inadequados tidos por qualquer pessoa em determinado período de tempo ${ }^{(1)}$.

Não fosse assim e a endoscopia associada a biopsias poria fim a todos os outros métodos diagnósticos da DRGE. Ao contrário, o estudo eletromotor do esôfago também tem papel estabelecido na aferição da doença. É o único método que pode detectar hipotensão do esfíncter inferior do esôfago e o comportamento motor do órgão como um todo, não só pesquisando afecção associada, como também a resposta do órgão ao refluxo ou ainda fatores funcionais predisponentes à $\mathrm{DRGE}^{(2)}$. Se realizado durante 24 horas, é capaz de avaliar o número de relaxamentos transitórios do esfíncter, bem como sua duração.

Atualmente dispõe-se do Bilitec, para detecção do refluxo biliar. A mistura ácido-bile, após refluxo duodenogástrico, freqüentemente apresenta $\mathrm{pH}$ final entre 4 e 7, o que faz com que a pHmetria esofágica não registre refluxo gastroesofágico de grande potencial agressor à mucosa.

Talvez a DRGE constitua o mais exuberantemente variado quadro dentre as várias doenças do aparelho digestivo. Sua riqueza de fatores de ataque e defesa, com suas diferentes gradações, e os vários recursos diagnósticos disponíveis, complementares entre si, instigam a curiosidade científica continuamente e exigem muitos conhecimentos dos que se propõem a atender tais pacientes e muitos cuidados àqueles que se dedicam a publicações sobre o assunto.

Valter Nilton FELIX*

Felix VN. Diagnosis of the gastroesophageal reflux disease: options and criteria. Arq Gastroenterol 2000;37(4):195-196.

HEADINGS - Esophagitis. Gastroesophageal reflux.

\section{REFERÊNCIAS BIBLIOGRÁFICAS}

1. Collins BJ, Elliot H, Sloan JM, MacFarlane RJ, Love AH. Esophageal histology in reflux esophagitis. J Clin Pathol 1985;38:1265.

2. Felix VN, Cecconello I, Pinotti HW. Alterações motoras do esôfago na esofagite de refluxo - causas ou conseqüências? ABCD Arq Bras Cir Dig 1992; 7(Supl.1):38.

3. Felix VN. Assessment of esophageal pH monitoring. ABCD Arq Bras Cir Dig 1995;10:61
4. Felix VN, Viebig RG. A importância da pHmetria esofágica prolongada na pesquisa do refluxo gastroesofágico patológico em crianças. Arq Gastroenterol 1999;36:201.

5. Flora-Filho R, Câmara-Lopes LH, Zilberstein B. Critérios histológicos de esofagite na doença do refluxo gastroesofágico. Reavaliação da sensibilidade da pHmetria esofágica de 24 horas. Arq Gastroenterol 2000;37:197-202.

6. Rosen SN, Pope II CE. Extended esophageal $\mathrm{pH}$ monitoring - an analysis of the literature and assessment of its role in the diagnosis and management of gastroesophageal reflux. J Clin Gastroenterol 1989;11:260.

* Professor Livre-Docente do Departamento de Gastroenterologia da Faculdade de Medicina da Universidade de São Paulo. 